\title{
The variation of psychopharmacological prescription rates for people with autistic spectrum disorder (ASD) in 30 countries
}

\begin{abstract}
Angel Y.S. Wong ${ }^{1}$, Yingfen Hsia ${ }^{1,5}$, Esther W. Chan ${ }^{1}$, Declan G.M. Murphy ${ }^{2}$, Emily Simonoff ${ }^{3}$, Jan K. Buitelaar ${ }^{4}$, Ian C.K. Wong ${ }^{1,5}$

${ }^{1}$ Centre for Safe Medication Practice and Research, Department of Pharmacology and Pharmacy, Li Ka Shing Faculty of Medicine, The University of Hong Kong, Hong Kong SAR, China.

${ }^{2}$ Sackler Institute for Translational Neurodevelopmental Research and the Department of Forensic and Developmental Sciences, King's College London, Institute of Psychiatry, London, United Kingdom.
\end{abstract}

${ }^{3}$ Department of Child and Adolescent Psychiatry, King's College London, Institute of Psychiatry and Biomedical Research Centre for Mental Health, London, United Kingdom.

${ }^{4}$ Radboud University Nijmegen Medical Center, Donders Institute for Brain, Cognition and Behavior, Department of Cognitive Neuroscience, Nijmegen, the Netherlands

${ }^{5}$ Centre for Paediatric Pharmacy Research, Department of Practice and Policy, UCL School of Pharmacy, University College London, London, United Kingdom

Running title: Variation of prescription rates for ASD

Correspondence:

Professor Ian Chi Kei Wong

Centre for Safe Medication Practice and Research, Department of Pharmacology and Pharmacy, Li Ka Shing Faculty of Medicine, The University of Hong Kong, Hong Kong SAR, China. 
Telephone: (852) 28199441

Fax: (852) 28170859

Email: wongick@hku.hk

\section{Acknowledgements of funding}

The research leading to these results has received support from the Innovative Medicines Initiative (IMI) Joint Undertaking under grant agreement no. 115300: European Autism Interventions (EU-AIMS), resources of which are composed of financial contribution from the European Union's Seventh Framework Programme (FP7/2007-2013) and EFPIA companies in kind contribution. DM, IW, and ES also received funding from the National Institute of Health Research (UK) for a program grant on this topic and for the neurodevelopmental theme in Biomedical Research Centre at the Institute of Psychiatry, London, United Kingdom.

\section{Conflicts of interest}

ES, YH, EWC and AW have no conflicts of interest. DGM has received research funding and honoraria from various pharmaceutical companies, including Shire and Janssen-Cilag and in the past has received honoraria from Janssen-Cilag and Wyeth. He is currently receiving funding from the IMI for EU-AIMS to identify new treatment targets for ASD.

JB has been in the past 3 years a consultant to / member of advisory board of / and/or speaker for Janssen Cilag BV, Eli Lilly, Shire, Novartis, Roche and Servier. He is not an employee of any of these companies, and not a stock shareholder of any of these companies. He has no other financial or material support, including expert testimony, patents and royalties. He is currently receiving funding from the European Union's Seventh Framework Programme to investigate the 
safety of risperidone in children (PERS), the long-term safety of methylphenidate (ADDUCE) and EU-AIMS to identify new treatment targets for ASD.

IW has received research funding and honoraria from various pharmaceutical companies, including Shire, Janssen-Cilag and Bristol-Myers Squibb. He is currently receiving funding from the European Union's Seventh Framework Programme to investigate the safety of risperidone in children (PERS) and the long-term safety of methylphenidate (ADDUCE). He is also a director of Healthcare Innovation Technology Service Limited which received funding from the IMI for taking part in the EU-AIMS project. 


\section{Scientific Abstract}

There is significant variation in prescriptions among countries in clinical practice for the treatment of autism spectrum disorder (ASD). It has also been suggested that many people with mental health disorders in low/middle-income countries do not receive adequate treatment. Hence, this study investigated psychopharmacological treatment patterns for ASD in thirty countries and the association between the country's income and ASD prescription rates.

The IMS Prescribing Insights database was used to investigate the prescription patterns for ASD treatment in 2007-2012. Data were obtained from 30 countries in the continents of Europe, Asia, Oceania, Central America, South America and Africa. The Gross Domestic Product (GDP) per capita was used as a proxy for the country's income. Spearman correlation was used to examine the association between prescription rate and GDP per capita.

The highest prescription rate was found in Europe (1.34-36.36/10,000) while the lowest prescription rates were found in Asian countries, such as Turkey, Indonesia, Saudi Arabia and Pakistan (0.04-0.82/10,000). The most common prescribed drug for ASD treatment in most of the countries was risperidone, but antidepressants and anti-epileptic drugs were also frequently prescribed. There was a significant positive correlation between GDP per capita and prescription rate $($ Spearman $\rho=0.60 ; \mathrm{p}=0.0011 ; 95 \%$ CI $0.27-0.81)$, that is, the higher the GDP per capita, the higher the prescription rate.

There are marked international differences in prescription rates for ASD, and this is partially accounted by economic factors. Future research should combine more data for ASD treatment to inform on the disparity of psychopharmacological treatment between countries.

\section{(249 words)}




\section{Lay Abstract}

There is wide variation in prescriptions among countries in clinical practice for the treatment of autism spectrum disorder (ASD). Many people with mental health disorders living in countries classified as low/middle income do not receive adequate treatment. Therefore, this study investigated psychopharmacological treatment patterns for ASD in thirty countries and the association between the country's income and ASD prescription rates.

An international healthcare information database (The IMS Prescribing Insights database) was used to investigate the prescription patterns for ASD treatment in 2007-2012. Data were obtained from 30 countries in the continents of Europe, Asia, Oceania, Central America, South America and Africa. The Gross Domestic Product (GDP) per capita was used as an indicator for the country's income. Spearman correlation, a statistical model, was used to examine the association between prescription rate and GDP per capita.

The highest prescription rate was found in Europe $(1.34-36.36 / 10,000)$ while the lowest prescription rates were found in Asian countries, such as Turkey, Indonesia, Saudi Arabia and Pakistan (0.04-0.82/10,000). The most common prescribed drug for ASD treatment in most of the countries was risperidone, but antidepressants and anti-epileptic drugs were also frequently prescribed. The result implied the higher the GDP per capita, the higher the prescription rate between countries.

There are marked international differences in prescription rates for $\mathrm{ASD}$, and this is partially accounted by economic factors. Future research should combine more data for ASD treatment to develop an understand of the disparity of psychopharmacological treatment between countries. 


\section{(242 words)}

\section{Introduction}

Autism spectrum disorder (ASD) is a neurodevelopmental condition characterised by impaired social and communicative behaviour as well as rigid and stereotyped patterns of behaviour (American Psychiatric Association, 1994; World Health Organization). ASD is often comorbid in many individuals with mental health conditions including anxiety and mood disorders, attention-deficit hyperactivity disorder (ADHD), seizure disorder, sleep disorder and learning disabilities (Bradley \& Bolton, 2006; MacNeil, Lopes, \& Minnes, 2009; Matson \& Neal, 2009; Simonoff et al., 2008; Souders et al., 2009). Recent epidemiological studies report a prevalence of ASD of approximately $1.1 \%$ in children and adolescents in the United Kingdom (UK) and the United States (US) (Baird et al., 2006; Kogan et al., 2009), but the prevalence varies in different countries and across studies (Elsabbagh et al., 2012). Approximately $70 \%$ of individuals with ASD suffer from additional mental conditions (Simonoff et al., 2008).

The clinical management of ASD aims to maximise the affected individual's functional independence and quality of life, and to mitigate carer's distress and burden (Carbone, Farley, \& Do, 2010; Myers, Johnson, \& American Academy of Pediatrics Council on Children With Disabilities, 2007) by minimising core symptoms, lowering the impact of associated mental health symptoms and reducing maladaptive behaviours (Cadman et al., 2012). It includes educational and behavioural programmes and pharmacological treatment as an adjunct in the management of ASD (Myers et al., 2007). There are currently no highly effective pharmacological treatments for the core symptoms of ASD, therefore current approaches target the minimisation of comorbid symptoms. Currently, however, there are limited practical guidelines for the pharmacological treatments of associated symptoms in children and 
adolescents with ASD (Frazier et al., 2011). In the US, only risperidone and aripiprazole are approved by the Food and Drug Administration (FDA) for the treatment of irritability in children with ASD (Marcus et al., 2009; Owen et al., 2009; Shea et al., 2004). In other western countries, risperidone is also approved for the indication of behavioural disturbance among children and adolescents with ASD by the European Medicines Agency (EMA), the Medicines and Healthcare Products Regulatory Agency (MHRA) of the UK, and the Australian Therapeutic Goods Administration (TGA) (European Medicines Agency, 2007; World Health Organization, 2013). Despite insufficient evidence on efficacy and long-term safety of psychotropic drugs for ASD treatment, various medications have been used for ASD treatment in clinical practice such as $\alpha$-adrenergic agents, $\beta$ blockers, mood stabilisers (or antiepileptics) and antipsychotics (Hollander, Phillips, \& Yeh, 2003; McPheeters et al., 2011; Myers et al., 2007; Rosenberg et al., 2010).

Previous studies have estimated that approximately $27 \%$ to $60 \%$ of children and adolescents received at least one medication for ASD treatment in the US and Canada (Coury et al., 2012; Frazier et al., 2011; Mandell et al., 2008). In the UK, a study using a primary care database reported approximately $29 \%(1,619 / 5,651)$ of young people aged $0-24$ years with ASD received psychotropic drugs; and the commonly prescribed drug classes were sleep medications (9.7\%), stimulants (7.9\%), and antipsychotics (7.3\%) (Murray et al., 2013). Although previous studies have demonstrated the prescription patterns of ASD treatment in the US and the UK, the generalisability of the findings to other countries is unknown. This is of relevance due to geographic and cultural differences, as well as potential variations in clinical practice [22]. A face-to-face interview survey study conducted by the World Health Organisation (WHO) in 17 countries showed that the proportion of patients with mental health disorders (e.g. anxiety, mood 
and substance disorders) receiving either pharmacotherapy ( $\geq 1$ month of a medication, plus $\geq 4$ visits to medical doctor) or psychotherapy ( $\geq 8$ visits with any professional) was smaller in low and middle-income countries as compared with high-income countries (Wang et al., 2007). In addition, it suggested that the majority of people with mental health disorders in low/middle income countries do not receive the treatment that they need (Lund et al., 2012). In our previous work, we demonstrated significant variation in psychopharmacological prescription patterns between 2010 and 2012 in children and adolescents with ASD across ten countries (Hsia et al., 2013). However, we did not investigate the extent to which a country's income is associated with variation in drug treatment. Also to date, there are very limited cross-national studies on ASD treatment available. Therefore, we conducted a descriptive comparison of prescription rates in 30 countries that previously had no published data. We investigated whether a country's income was associated with ASD treatment.

\section{Method}

\section{Data source}

This was a descriptive study using the IMS Prescribing Insights (MIDAS) database to investigate prescriptions issued for patients with a diagnosis of ASD in 30 countries. The IMS MIDAS database is an audit drawn from a representative sample of practitioners in each country and contains diagnoses and prescription data from different countries (Wong \& Murray, 2005). The prescription data of sampled doctors were adjusted according to different stratification methods (see Table 1), and a projected national total of prescriptions data per year was calculated for each country. Table 1 summarises the details of data collection including the number of doctors involved, stratification methods, and reporting time for each country. Previous studies have used the MIDAS database to investigate the prescription trends and patterns of psychotropic 
prescriptions (Balkrishnan, Phatak, Gleim, \& Karve, 2009; Livermore et al., 2006; Wong, Murray, Camilleri-Novak, \& Stephens, 2004). Therefore, this database is suitable for investigating the prescription patterns at a global level.

\section{Study population}

Prescriptions for patients with a diagnosis of ASD were identified using International Classification of Disease (ICD), tenth revision codes under F84 (Pervasive Development Disorder; PDD) (Supplementary Online Material 1) between January 2007 and December 2012 (study period) in the IMS MIDAS database. Data were obtained from 12 European countries (Austria, Belgium, Netherlands, Finland, Ireland, Switzerland, Greece, Czech Republic, Hungary, Poland, Portugal, Slovakia), six Asian countries (South Korea, Thailand, Indonesia, Pakistan, Turkey, Saudi Arabia), two South American countries (Colombia, Venezuela), two countries in the Oceania (Australia, New Zealand), and two African countries (Egypt, South Africa). The prescription data of Central America were drawn from sampled physicians in Guatemala, Honduras, El Salvador, Nicaragua, Costa Rica, and Panama then adjusted according to the stratifications to obtain six countries' projected prescriptions. Therefore, "Central America" was used to represent six countries' projected prescription data throughout this study.

\section{Drug prescribing}

We used several drug categories to classify ASD treatment: (1) stimulants (atomoxetine, dexamfetamine, methylphenidate), (2) antidepressants, (3) antipsychotics, antiepileptics/mood stabilisers, (5) benzodiazepines, (6) sleep medications (including melatonin), (7) clonidine, (8) beta-blockers, (9) antiparkinson medication, and (10) anxiolytics. 


\section{Estimated prescription rate}

The "average annual projected number of prescriptions" was calculated by the summation of the projected number of prescriptions between 2007 and 2012 (inclusive); followed by the division of the sum by 6 . The estimated annual prescription rates were calculated by dividing "average annual projected number of prescriptions" by the estimated annual population. The estimated annual population figures for each country in 2010 were obtained from the United Nations, Department of Economic and Social Affairs: (http://esa.un.org/wpp/excel-Data/population.htm). By using the average of six-year data, it can reduce random variation within the data. As noted above, it has been reported that people with mental health disorders receive less treatment in low/middle income countries compared with high income countries (MacArthur \& The Academy of Medical Sciences, 2008). In order to investigate whether low/middle income countries is associated with lower ASD treatment compared to high income countries, the Gross Domestic Product (GDP) per capita in US dollars in 2010 was used as an indicator of each county's living standard and its association with ASD treatment calculated. The GDP per capita data were obtained from the United Nations, National Accounts Main Aggregates Database: (http://unstats.un.org/unsd/snaama/dnllist.asp). For Central America, the GDP per capita was the mean of the sum of GDP per capita of the six countries.

\section{Data analysis}

We analysed the data by drug class and by individual drug for each country. Spearman correlation was used to investigate the association between prescription rate and GDP per capita; this was selected (rather than Pearson correlation) because it is less sensitive to outliers, which may occur in relation to GDP per capita figures. Data management and analyses were performed 
using Microsoft Excel 2010 ${ }^{\circledR}$, Statistical Analysis System (SAS) v9.3 (SAS Inc, United States), and Stata MP version 11.2 (StataCorp, College Station, TX, United State).

\section{Results}

There was a wide range of estimated prescription rates in different countries between 2007 and 2012 (Table 2). The European countries were found to have highest prescription rate (1.34$36.36 / 10,000)$. The lowest prescription rates were observed in Egypt $(0.74 / 10,000)$, Venezuela $(0.83 / 10,000)$ and Asian countries such as Turkey, Saudi Arabia, Indonesia and Pakistan (0.04$0.82 / 10,000)$.

Figure 1 shows the proportion of different psychotropic class for ASD treatment by country between 2007 and 2012. Antipsychotics were the most commonly prescribed drug class for ASD treatment in all countries except Austria, Finland and New Zealand. In Finland, benzodiazepines (27.7\%) and anxiolytics (22.1\%) were the most commonly prescribed drug classes for ASD treatment. Antidepressants were the second most commonly prescribed drug class in Australia, South Africa and most of European countries except the Czech Republic, Hungary, Poland, Portugal, and Slovakia. Antiepileptics were the second most commonly prescribed drug class in the Czech Republic, Hungary, Poland, Portugal and Slovakia.

There was a significant positive relation between GDP per capita and prescription rate (Spearman's coefficient $\rho=0.60 ; \mathrm{p}=0.0011$ (Figure 2). In general, countries with low GDP per capita have low estimated prescription rates. However, it is important to note that this was not universally the case. For instance, some countries (e.g. Switzerland, Austria, Finland and Australia) have high GDP per capita but low estimated prescription rates for ASD treatment; in contrast Colombia and Thailand have low GDP per capita but high estimated prescription rates. 
Table 3 shows the most common drug prescribed for ASD treatment in each country. Risperidone was a commonly prescribed drug in all countries except Finland. Buspirone (an anxiolytic) was the drug most commonly prescribed for ASD treatment in Finland. Stimulants (methylphenidate, atomoxetine) and anti-epileptic drugs (e.g. lamotrigine, carbamazepine, valproic acid) were also prescribed for treatment in most countries.

\section{Discussion}

There is considerable variation in prescription rates among countries. The variation of psychopharmacological prescription patterns may be explained by a number of factors such as socioeconomic status, awareness or levels of knowledge about ASD, perceptions towards ASD treatment and access to health services. In general, antipsychotic drugs were the most frequently prescribed drug class for ASD and risperidone was commonly prescribed in all countries. There are two FDA-approved medications (risperidone and aripiprazole) licensed for the treatment of irritability or aggression in patients with ASD. Risperidone is also labelled for the treatment of behavioural problems in people with ASD in some countries including European countries. In addition, as risperidone is off-patent and the generic products are more affordable than aripiprazole, this may explain its popularity as ASD treatment.

Stimulants, antiepileptics, mood stabilisers, and antidepressants were also frequently prescribed for ASD treatment in our study. However, as we do not have the information on the individuals' co-morbidities, we do not know whether these drugs are being used for the treatment of ASD symptoms or other psychiatric co-morbidities. Since there are very limited data on the efficacy and long term adverse reactions of these drugs in patients with ASD, further research is warranted. 
There was significant association between psychotropic drug use for ASD treatment and GDP per capita. Our results indicate that in general countries with low GDP tend to have low prescription rates. Low prescription rates found in low/middle countries could be due to smaller health budgets to mental health policy and services. A study involving 191 countries reported that a smaller proportion of health budget was allocated to mental health in lower income countries compared with higher income countries. In addition, many low income countries relied on out-of-pocket expenditure (Saxena, Sharan, \& Saraceno, 2003). In comparison to tax-based and insurance-based for health care financing, out-of-pocket expenditure could create financial burdens for the patients and their families, and thus may lower the rate of receiving services in the low/middle income countries. Another survey reported a similar association between the overall expenditures on health care and percentage of patients receiving services (Wang et al., 2007). In 2006, the Academy of Medical Sciences showed that the limited access to mental health treatment among patients living in lower/middle income countries compared to higher income countries (MacArthur \& The Academy of Medical Sciences, 2008). It also reported that low availability of mental health professionals in low/middle income countries may impact on this. For instance, there is up to a 200 -fold difference between some countries in the number of available psychiatrists, nurses, psychologists and social workers. This means there are, on average, five psychiatrists per million people in low/middle income countries as compared to 40 psychiatrists per million people in the UK. In addition to limited access to health services, patients who initiate treatments for mental disorders receive much less follow-up care in low/middle income countries as compared with high income countries (Wang et al., 2007). Reduced follow-up care could also contribute to the lower prescription rates in low/middle income countries. Further research is needed to obtain more detailed data to investigate the 
association between ASD treatment and health care expenditures on mental health in different countries.

To our knowledge, this is the largest multi-national comparison of psychopharmacological use in ASD treatment. However, there are notably several limitations. First, as IMS MIDAS is not a patient-based medical record database, we were unable to report the number of patients who visited physicians for ASD treatment in this study. Consequently, we cannot estimate the treatment rates in patients with ASD. Second, our stratified sampling was intended to provide a representative sample for each country. However some patients may be under the care of psychiatrists for the management of ASD-related symptoms and the sample of clinicians we had access to only represent a small percentage of psychiatrists. Therefore, the audit may have underestimated the number of prescriptions. Third, we were unable to obtain data on co-morbidities, so we do not know whether psychotropic drugs were prescribed for the treatment of core symptoms of ASD or for other psychiatric co-morbidities. Lastly, despite the significant positive correlation between GDP per capita and prescription rate for ASD treatment, potential confounders could not be adjusted for due to limited information in the dataset (e.g. age of the patients and the use of complementary/ 'alternative' treatments). 


\section{Conclusion}

There is wide variation in the psychopharmacological treatment of ASD among countries. In general, European countries have the highest prescription rate compared to those in Asian regions. Also there is an association between psychotropic drug use and GDP per capita in most (but not all) countries. Future research should incorporate more data including treatment rates, age of the patients and the use of complementary or alternative treatments for ASD in different countries to develop an in-depth understand of the disparity of psychopharmacological treatment between countries.

Total words: 2318 
Table 1 Method of data collection in each country

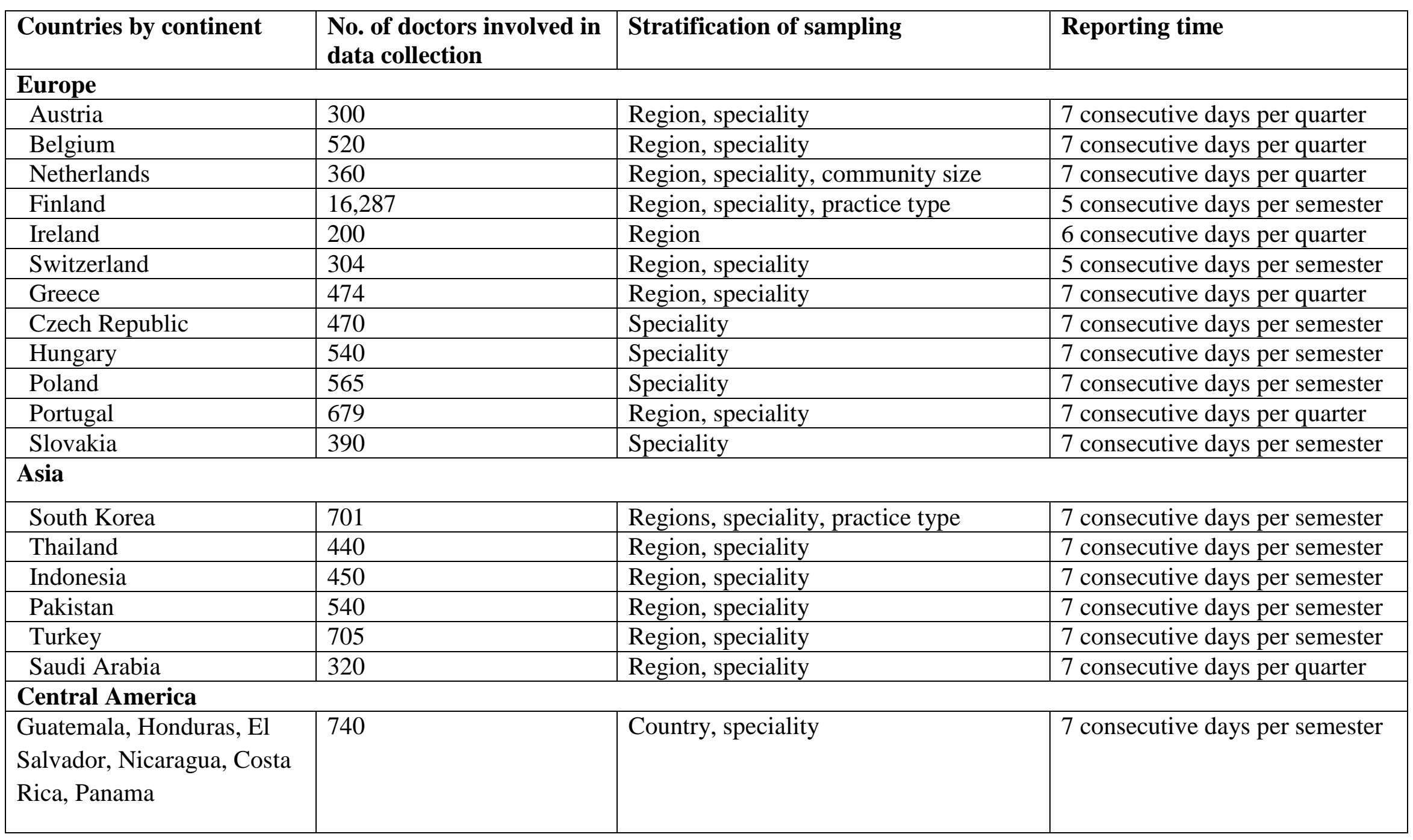




\section{Continue.}

\begin{tabular}{|l|l|l|l|}
\hline Countries by continent & $\begin{array}{l}\text { No. of doctors involved in } \\
\text { data collection }\end{array}$ & Stratification of sampling & Reporting time \\
\hline South America & 385 & Region, speciality, practice type & 7 consecutive days per semester \\
\hline Colombia & 500 & Region, speciality & 7 consecutive days per semester \\
\hline Venezuela & \multicolumn{5}{|l|}{} \\
\hline Australia & Region, speciality & 7 consecutive days per quarter \\
\hline Australia & 200 & Region & 7 consecutive days per quarter \\
\hline New Zealand & \multicolumn{5}{|l|}{} \\
\hline Africa & 525 & $\begin{array}{l}\text { Region, speciality } \\
\text { location of general practitioner's } \\
\text { practice (metropolitan or non- } \\
\text { metropolitan) }\end{array}$ & 7 consecutive days per quarter \\
\hline South Africa & 384 & \multicolumn{2}{|l|}{ consecutive days per quarter } \\
\end{tabular}


Table 2 Estimated prescription rates for autistic spectrum disorder (ASD) treatment in 2007-2012a

\begin{tabular}{|c|c|c|c|}
\hline Country & $\begin{array}{l}\text { Average projected number of } \\
\text { prescriptions for patients } \\
\text { with ASD per year }\end{array}$ & Estimated population in $2010^{\mathrm{b}}$ & $\begin{array}{c}\text { Estimated prescription rate } \\
\text { (number of ASD prescriptions per } \\
10,000 \text { people } \\
\text { in the general public) } \\
\text { c }\end{array}$ \\
\hline \multicolumn{4}{|l|}{ Europe } \\
\hline Austria & 3,269 & $8,394,000$ & 3.89 \\
\hline Belgium & 34,010 & $10,712,000$ & 31.75 \\
\hline Netherlands & 60,400 & $16,613,000$ & 36.36 \\
\hline Finland & 2,150 & $5,365,000$ & 4.01 \\
\hline Ireland & 2,656 & $4,470,000$ & 5.94 \\
\hline Switzerland & 11,764 & $7,664,000$ & 15.35 \\
\hline Greece & 1,526 & $11,359,000$ & 1.34 \\
\hline Czech Republic & 4,105 & $10,493,000$ & 3.91 \\
\hline Hungary & 1,683 & $9,984,000$ & 1.69 \\
\hline Poland & 15,192 & $38,277,000$ & 3.97 \\
\hline Portugal & 10,690 & $10,676,000$ & 10.01 \\
\hline Slovakia & 3,056 & $5,462,000$ & 5.59 \\
\hline \multicolumn{4}{|l|}{ Asia } \\
\hline South Korea & 69,184 & $48,184,000$ & 14.36 \\
\hline Thailand & 69,010 & $69,122,000$ & 9.98 \\
\hline Indonesia & 9,587 & $239,871,000$ & 0.40 \\
\hline Pakistan & 651 & $173,593,000$ & 0.04 \\
\hline Turkey & 5,941 & $72,752,000$ & 0.82 \\
\hline Saudi Arabia & 1389 & $27,448,000$ & 0.51 \\
\hline \multicolumn{4}{|l|}{ Central America } \\
\hline $\begin{array}{l}\text { Guatemala, Honduras, El } \\
\text { Salvador, Nicaragua, Costa } \\
\text { Rica, Panama }\end{array}$ & 4,924 & $42,146,000$ & 1.17 \\
\hline
\end{tabular}


Continue.

\begin{tabular}{|c|c|c|c|}
\hline Country & $\begin{array}{l}\text { Average projected number of } \\
\text { prescriptions for patients with } \\
\text { ASD per year }\end{array}$ & Estimated population in $2012^{\mathrm{b}}$ & $\begin{array}{c}\text { Estimated prescription rate } \\
\text { (number of ASD prescriptions } \\
\text { per } 10,000 \text { people in the general } \\
\text { public) })^{\mathrm{c}}\end{array}$ \\
\hline \multicolumn{4}{|l|}{ South America } \\
\hline Colombia & 29,678 & $46,295,000$ & 6.41 \\
\hline Venezuela & 2,400 & $28,980,000$ & 0.83 \\
\hline \multicolumn{4}{|l|}{ Oceania } \\
\hline Australia & 6,103 & $22,268,000$ & 2.74 \\
\hline New Zealand & 3,553 & $4,368,000$ & 8.13 \\
\hline \multicolumn{4}{|l|}{ Africa } \\
\hline Egypt & 6,039 & $81,121,000$ & 0.74 \\
\hline South Africa & 6,631 & $50,133,000$ & 1.32 \\
\hline
\end{tabular}

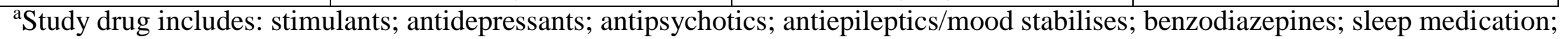
clonidine; beta-blockers; antiparkinsonians; other anxiolytics.

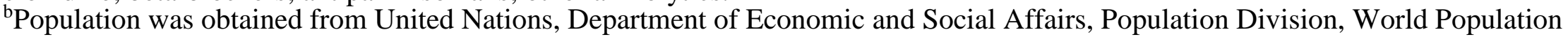
Prospects. Available from http://esa.un.org/unpd/wpp/Excel-Data/population.htm.

${ }^{\mathrm{c}}$ Numbers presented in 2 decimal places. 
Figure 1 Percentage of different psychotropic drug classes for the treatment of autistic spectrum disorder ${ }^{\mathrm{a}}$

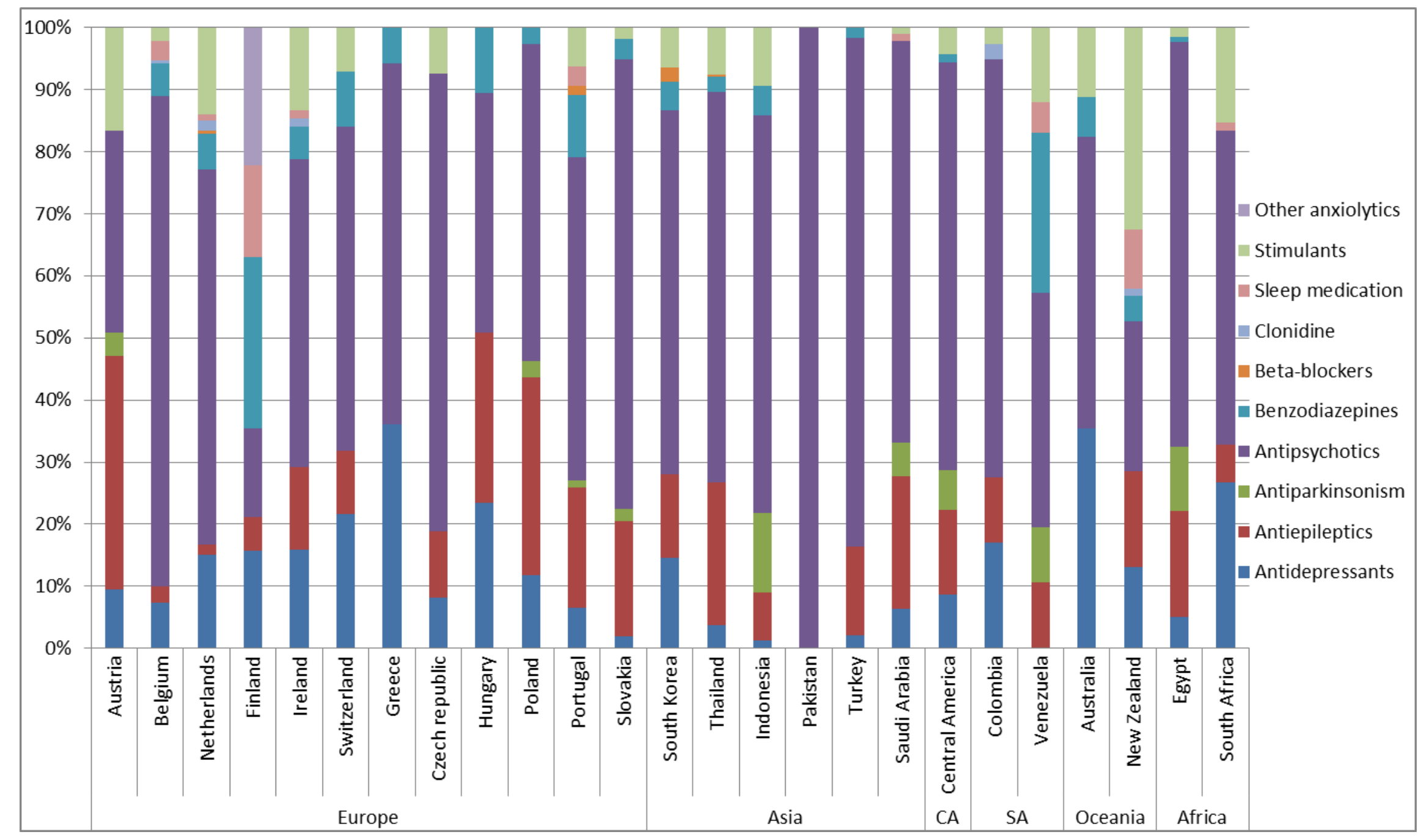

${ }^{\mathrm{a}} \mathbf{C A}=$ Central America; $\mathbf{S A}=$ South America. 
Figure 2 Scatter plot of estimated prescription rates for autistic spectrum disorder (ASD) treatment versus Gross Domestic Products (GDP) per capita in each country ${ }^{\mathrm{a}}$

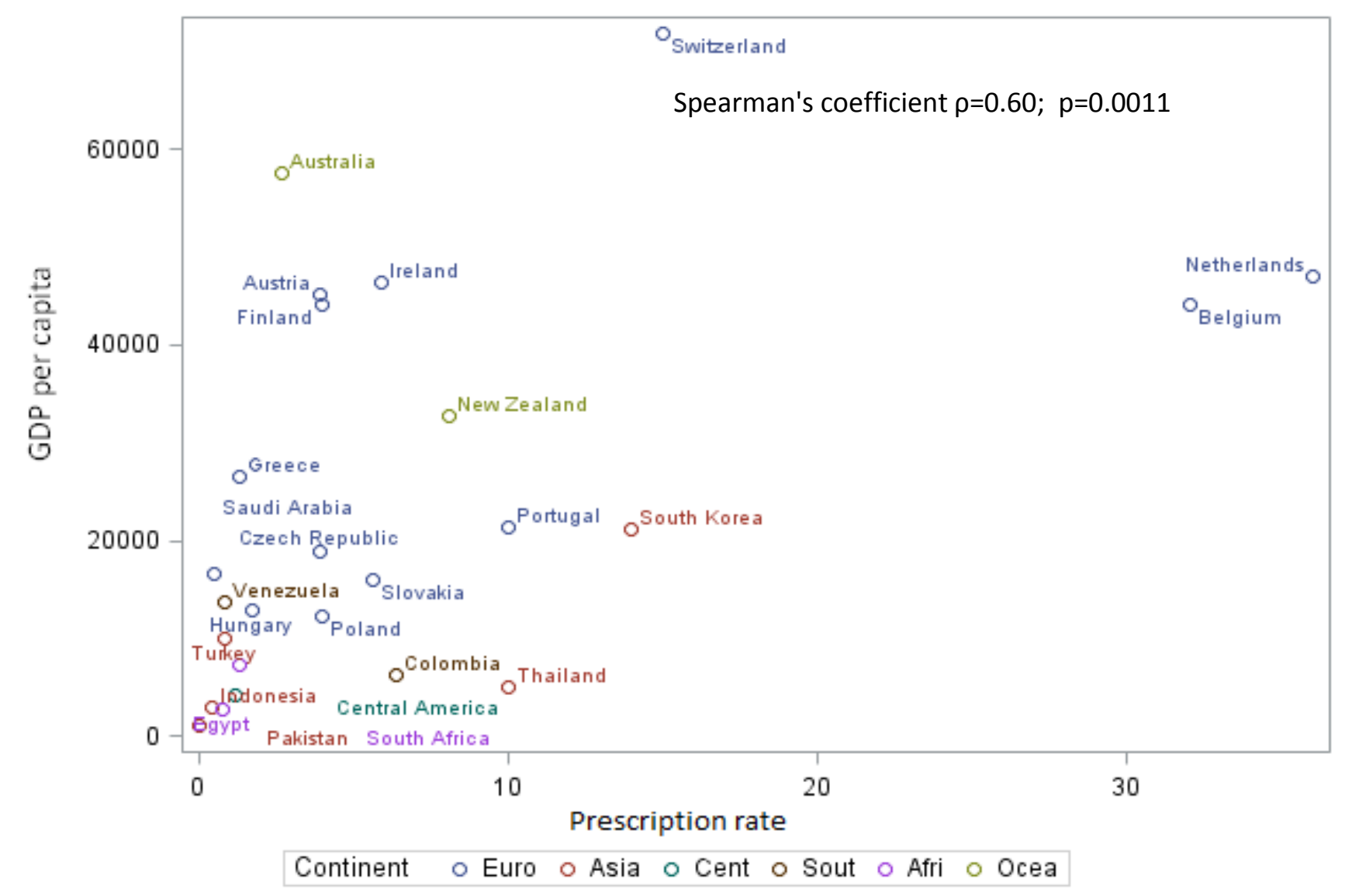

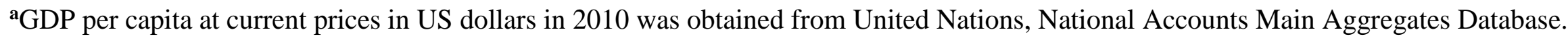
Available from http://unstats.un.org/unsd/snaama/dnllist.asp. 
Table 3 Common drugs prescribed for ASD treatment in 2007-2012

\begin{tabular}{|c|c|c|c|}
\hline Countries by region & Drug & $\begin{array}{l}\text { Projected number of } \\
\text { prescriptions per year }\end{array}$ & $\%$ \\
\hline \multicolumn{4}{|l|}{ Europe } \\
\hline \multirow[t]{4}{*}{ Austria } & Lamotrigine & 910 & 27.8 \\
\hline & Risperidone & 654 & 20.0 \\
\hline & Atomoxetine & 544 & 16.6 \\
\hline & Total projected prescriptions & 3,269 & 100.0 \\
\hline \multirow[t]{4}{*}{ Belgium } & Risperidone & 11,816 & 34.7 \\
\hline & Aripiprazole & 4,036 & 11.9 \\
\hline & Pipamperone & 2,671 & 7.9 \\
\hline & Total projected prescriptions & 34,010 & 100.0 \\
\hline \multirow[t]{4}{*}{ Netherlands } & Risperidone & 22,696 & 37.6 \\
\hline & Aripiprazole & 6,275 & 10.4 \\
\hline & Methylphenidate & 6,144 & 10.2 \\
\hline & Total projected prescriptions & 60,400 & 100.0 \\
\hline \multirow[t]{4}{*}{ Finland } & Buspirone & 451 & 21.0 \\
\hline & Escitalopram & 322 & 15.0 \\
\hline & Oxazepam & 303 & 14.1 \\
\hline & Total projected prescriptions & 2,150 & 100.0 \\
\hline \multirow[t]{4}{*}{ Ireland } & Zuclopenthixol & 497 & 18.7 \\
\hline & Risperidone & 431 & 16.2 \\
\hline & Methylphenidate & 354 & 13.3 \\
\hline & Total projected prescriptions & 2,656 & 100.0 \\
\hline \multirow[t]{4}{*}{ Switzerland } & Risperidone & 1,902 & 16.2 \\
\hline & Aripiprazole & 1,512 & 12.8 \\
\hline & Quetiapine & 905 & 7.7 \\
\hline & Total projected prescriptions & 11,764 & 100.0 \\
\hline \multirow[t]{5}{*}{ Greece } & Olanzapine & 509 & 33.3 \\
\hline & Risperidone & 241 & 15.8 \\
\hline & Clomipramine & 207 & 13.5 \\
\hline & Venlafaxine & 207 & 13.5 \\
\hline & Total projected prescriptions & 1,526 & 100.0 \\
\hline \multirow[t]{4}{*}{ Czech Republic } & Risperidone & 2,021 & 49.2 \\
\hline & Chlorprothixene & 403 & 9.8 \\
\hline & Atomoxetine & 308 & 7.5 \\
\hline & Total projected prescriptions & 4,105 & 100.0 \\
\hline \multirow[t]{4}{*}{ Hungary } & Carbamazepine & 300 & 17.8 \\
\hline & Risperidone & 296 & 17.6 \\
\hline & Zuclopenthixol & 189 & 11.2 \\
\hline & Total projected prescriptions & 1,683 & 100.0 \\
\hline
\end{tabular}




\section{Continue}

\begin{tabular}{|c|c|c|c|}
\hline Countries by region & Drug & $\begin{array}{l}\text { Projected number of } \\
\text { prescriptions per year }\end{array}$ & $\%$ \\
\hline \multirow[t]{4}{*}{ Poland } & Risperidone & 3,657 & 24.1 \\
\hline & Valproic acid & 1,869 & 12.3 \\
\hline & Lamotrigine & 1,614 & 10.6 \\
\hline & Total projected prescriptions & 15,192 & 100.0 \\
\hline \multirow[t]{4}{*}{ Portugal } & Risperidone & 3,709 & 34.7 \\
\hline & Methylphenidate & 659 & 6.2 \\
\hline & Valproic acid & 631 & 5.9 \\
\hline & Total projected prescriptions & 10,690 & 100.0 \\
\hline \multirow[t]{4}{*}{ Slovakia } & Risperidone & 747 & 24.4 \\
\hline & Clonazepam & 347 & 11.4 \\
\hline & Quetiapine & 294 & 9.6 \\
\hline & Total projected prescriptions & 3,056 & 100.0 \\
\hline \multicolumn{4}{|c|}{ 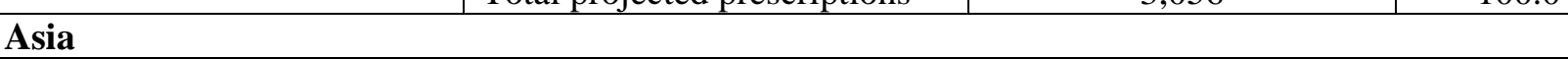 } \\
\hline \multirow[t]{4}{*}{ South Korea } & Risperidone & 32,792 & 47.4 \\
\hline & Methylphenidate & 4,285 & 6.2 \\
\hline & Valproic acid & 3,266 & 4.7 \\
\hline & Total projected prescriptions & 69,184 & 100.0 \\
\hline \multirow[t]{4}{*}{ Thailand } & Risperidone & 38,116 & 55.2 \\
\hline & Valproic acid & 13,496 & 19.6 \\
\hline & Methylphenidate & 5,113 & 7.4 \\
\hline & Total projected prescriptions & 69,010 & 100.0 \\
\hline \multirow[t]{4}{*}{ Indonesia } & Risperidone & 3,472 & 36.2 \\
\hline & Aripiprazole & 2,573 & 26.8 \\
\hline & Piracetam & 1,224 & 12.8 \\
\hline & Total projected prescriptions & 9,587 & 100.0 \\
\hline \multirow[t]{2}{*}{ Pakistan } & Risperidone & 651 & 100.0 \\
\hline & Total projected prescriptions & 651 & 100.0 \\
\hline \multirow[t]{5}{*}{ Turkey } & Risperidone & 4,427 & 74.5 \\
\hline & Carbamazepine & 372 & 6.3 \\
\hline & Valproic acid & 239 & 4.0 \\
\hline & Lamotrigine & 236 & 4.0 \\
\hline & Total projected prescriptions & 5,941 & 100.0 \\
\hline \multirow[t]{4}{*}{ Saudi Arabia } & Risperidone & 898 & 64.7 \\
\hline & Carbamazepine & 266 & 19.2 \\
\hline & Piracetam & 75 & 5.4 \\
\hline & Total projected prescriptions & 1,389 & 100.0 \\
\hline \multicolumn{4}{|l|}{ Central America } \\
\hline \multirow[t]{4}{*}{$\begin{array}{l}\text { Guatemala, Honduras, El } \\
\text { Salvador, Nicaragua, Costa } \\
\text { Rica, Panama }\end{array}$} & Risperidone & 2,608 & 53.0 \\
\hline & Haloperidol & 432 & 8.8 \\
\hline & Piracetam & 312 & 6.3 \\
\hline & Total projected prescriptions & 4,924 & 100.0 \\
\hline
\end{tabular}




\section{Continue}

\begin{tabular}{|c|c|c|c|}
\hline Countries by region & Drug & $\begin{array}{l}\text { Projected number of } \\
\text { prescriptions per year }\end{array}$ & $\%$ \\
\hline \multicolumn{4}{|l|}{ South America } \\
\hline \multirow{4}{*}{ Colombia } & Risperidone & 15,257 & 51.4 \\
\hline & Fluoxetine & 3,835 & 12.9 \\
\hline & Aripiprazole & 2,008 & 6.8 \\
\hline & Total projected prescriptions & 29,678 & 100.0 \\
\hline \multirow[t]{4}{*}{ Venezuela } & Risperidone & 789 & 32.9 \\
\hline & Clonazepam & 526 & 21.9 \\
\hline & Atomoxetine & 289 & 12.1 \\
\hline & Total projected prescriptions & 2,400 & 100.0 \\
\hline \multicolumn{4}{|l|}{ Oceania } \\
\hline \multirow[t]{4}{*}{ Australia } & Risperidone & 2,859 & 46.8 \\
\hline & Methylphenidate & 552 & 9.0 \\
\hline & Sertraline & 545 & 8.9 \\
\hline & Total projected prescriptions & 6,103 & 100.0 \\
\hline \multirow[t]{4}{*}{ New Zealand } & Methylphenidate & 958 & 27.0 \\
\hline & Risperidone & 556 & 15.6 \\
\hline & Melatonin & 338 & 9.5 \\
\hline & Total projected prescriptions & 3,553 & 100.0 \\
\hline \multicolumn{4}{|l|}{ Africa } \\
\hline \multirow[t]{4}{*}{ Egypt } & Risperidone & 3,792 & 62.8 \\
\hline & Piracetam & 632 & 10.5 \\
\hline & Carbamazepine & 548 & 9.1 \\
\hline & Total projected prescriptions & 6,039 & 100.0 \\
\hline \multirow[t]{4}{*}{ South Africa } & Risperidone & 3,158 & 47.6 \\
\hline & Citalopram & 1,688 & 25.5 \\
\hline & Methylphenidate & 924 & 13.9 \\
\hline & Total projected prescriptions & 6,631 & 100.0 \\
\hline
\end{tabular}


Supplementary Online Material 1: The International Classification of Diseases (ICD), tenth version codes to identify autistic spectrum disorder (ASD) patients

\begin{tabular}{ll}
\hline ICD 10 & Diagnosis \\
\hline F84 & Pervasive Development Disorder \\
F84.0 & Childhood autism \\
F84.1 & Atypical autism \\
F84.2 & Rett's syndrome \\
F84.3 & Other childhood disintegrative disorder \\
F84.4 & Overactive disorder associated with mental retardation and \\
& stereotyped movements \\
F84.5 & Asperger's syndrome \\
& Other pervasive developmental disorders \\
F84.8 & Pervasive developmental disorder, unspecified \\
F84.9
\end{tabular}




\section{Reference}

American Psychiatric Association. (1994). Diagnostic and Statistical Manual of Mental Diseases (DSM-IV) (4th ed.). Washington, DC: American Psychiatric Publishing.

Baird, G, Simonoff, E, Pickles, A, Chandler, S, Loucas, T, Meldrum, D, \& Charman, T. (2006). Prevalence of disorders of the autism spectrum in a population cohort of children in South Thames: the Special Needs and Autism Project (SNAP). Lancet, 368(9531), 210-215.

Balkrishnan, R, Phatak, H, Gleim, G, \& Karve, S. (2009). Assessment of the use of angiotensin receptor blockers in major European markets among paediatric population for treating essential hypertension. $J$ Hum Hypertens, 23(6), 420-425.

Bradley, E, \& Bolton, P. (2006). Episodic psychiatric disorders in teenagers with learning disabilities with and without autism. Br J Psychiatry, 189, 361-366.

Cadman, T, Eklund, H, Howley, D, Hayward, H, Clarke, H, Findon, J, ... Glaser, K. (2012). Caregiver Burden as People With Autism Spectrum Disorder and AttentionDeficit/Hyperactivity Disorder Transition into Adolescence and Adulthood in the United Kingdom. J Am Acad Child Adolesc Psychiatry, 51(9), 879-888.

Carbone, P.S., Farley, M, \& Do, T.D. (2010). Primary Care for Children with Autism. Am Fam Physician, 81(4), 453-460.

Coury, D.L., Anagnostou, E, Manning-Courtney, P, Reynolds, A, Cole, L, McCoy, R, . . Perrin, J.M. (2012). Use of psychotropic medication in children and adolescents with autism spectrum disorders. Pediatrics, 130 Suppl 2, S69-76.

Elsabbagh, M, Divan, G, Koh, Y.J., Kim, Y.S., Kauchali, S, Marcín, C, . . Fombonne, E. (2012). Global prevalence of autism and other pervasive developmental disorders. Autism Res, 5(3), 160-179.

European Medicines Agency. (2007). Assessment of the paediatric needs psychiatry. Retrieved 2 September 2013, from http://www.ema.europa.eu/docs/en_GB/document_library/Other/2009/10/WC500004 046.pdf

Frazier, T.W., Shattuck, P.T., Narendorf, S.C., Cooper, B.P., Wagner, M, \& Spitznagel, E.L. (2011). Prevalence and correlates of psychotropic medication use in adolescents with an autism spectrum disorder with and without caregiver-reported attention-deficit/hyperactivity disorder. J Child Adolesc Psychopharmacol, 21(6), 571-579.

Hollander, E, Phillips, A.T., \& Yeh, C.C. (2003). Targeted treatments for symptom domains in child and adolescent autism. Lancet, 362(9385), 732-734.

Hsia, Y, Wong, A.Y., Murphy, D.G.M., Simonoff, E, Buitelaar, J.K., \& Wong, I. C. (2013). Psychopharmacological prescriptions for people with autistic spectrum disorder (ASD): a multinational study. Psychopharmacology (Berl), [Epub ahead of print] doi: 10.1007/s00213-013-3263-x.

Kogan, M.D., Blumberg, S.J., Schieve, L.A., Boyle, C.A., Perrin, J.M., Ghandour, R.M., . . . van Dyck, P.C. (2009). Prevalence of Parent-Reported Diagnosis of Autism Spectrum Disorder Among Children in the US, 2007. Pediatrics, 124(5), 1395-1403.

Livermore, D.M., Reynolds, R, Stephens, P, Duckworth, G, Felmingham, D, Johnson, A.P., ... George, R.C. (2006). Trends in penicillin and macrolide resistance among pneumococci in the UK and the Republic of Ireland in relation to antibiotic sales to pharmacies and dispensing doctors. Int J Antimicrob Agents, 28(4), 273-279. 
Lund, C, Tomlinson, M, De Silva, M, Fekadu, A, Shidhaye, R, Jordans, M, .. Patel, V. (2012). PRIME: a programme to reduce the treatment gap for mental disorders in five low- and middle-income countries. PLoS Med, 9(12), e1001359.

MacArthur, G, \& The Academy of Medical Sciences. (2008). Challenges and priorities for global mental health research in low- and middle-income countries: symposium report.

Retrieved 4 July 2013, from http://www.eldis.org/go/topics/resource-guides/healthsystems/governance-and-health\&id=43964\&type=Document\#.UdUtFPk9Fio

MacNeil, B.M., Lopes, V.A., \& Minnes, P.M. (2009). Anxiety in children and adolescents with autism spectrum disorders. Res Autism Spectrum Disord, 3, 1-21.

Mandell, D.S., Morales, K.H., Marcus, S.C., Stahmer, A.C., Doshi, J, \& Polsky, D.E. (2008). Psychotropic medication use among Medicaid-enrolled children with autism spectrum disorders. Pediatrics, 121(3), e441-e448.

Marcus, R.N., Owen, R, Kamen, L, Manos, G, McQuade, R.D., Carson, W.H., \& Aman, M.G. (2009). A placebo-controlled, fixed-dose study of aripiprazole in children and adolescents with irritability associated with autistic disorder. J Am Acad Child Adolesc Psychiatry, 48(11), 1110-1119.

Matson, J.L. , \& Neal, D (2009). Seizures and epilepsy and their relationship to autism spectrum disorders. Res Autism Spectrum Disorder, 3(4), 999-1005.

McPheeters, M.L., Warren, Z, Sathe, N, Bruzek, J.L., Krishnaswami, S, Jerome, R.N., \& VeenstraVanderweele, J. (2011). A Systematic Review of Medical Treatments for Children With Autism Spectrum Disorders. Pediatrics, 127(5), e1312-1321.

Murray, M.L., Hsia, Y, Glaser, K, Simonoff, E, Murphy, D.G., Asherson, P.J., . . Wong, I.C. (2013). Pharmacological treatments prescribed to people with autism spectrum disorder (ASD) in primary health care. Psychopharmacology (Berl), [Epub ahead of print] doi: 10.1007/s00213-013-3140-7.

Myers, S.M., Johnson, C.P., \& American Academy of Pediatrics Council on Children With Disabilities. (2007). Management of children with autism spectrum disorders. Pediatrics, 120(5), 1162-1182.

Owen, R, Sikich, L, Marcus, R.N., Corey-isle, P, Manos, G, McQuade, R.D., . . . Findling, R.L. (2009). Aripiprazole in the treatment of irritability in children and adolescents with autistic disorder. Pediatrics, 124(6), 1533-1540.

Rosenberg, R.E., Mandell, D.S., Farmer, J.E., Law, J.K., Marvin, A.R., \& Law, P.A. (2010). Psychotropic medication use among children with autism spectrum disorders enrolled in a national registry, 2007-2008. J Autism Dev Disord, 40(3), 342-351.

Saxena, S, Sharan, P, \& Saraceno, B. (2003). Budget and financing of mental health services: baseline information on 89 countries from WHO's project atlas. J Ment Health Policy Econ, 6(3), 135-143.

Shea, S, Turgay, A, Carroll, A, Schulz, M, Orlik, H, Smith, I, \& Dunbar, F. (2004). Risperidone in the treatment of disruptive behavioral symptoms in children with autistic and other pervasive developmental disorders. Pediatrics, 114(5), e634-641.

Simonoff, E, Pickles, A, Charman, T, Chandler, S, Loucas, T, \& Baird, G. (2008). Psychiatric disorders in children with autism spectrum disorders: prevalence, comorbidity, and associated factors in a population-derived sample. J Am Acad Child Adolesc Psychiatry, 47(8), 921-929.

Souders, M. C., Mason, T. B., Valladares, O., Bucan, M., Levy, S. E., Mandell, D. S., . . PintoMartin, J. (2009). Sleep behaviors and sleep quality in children with autism spectrum disorders. Sleep, 32(12), 1566-1578. 
Wang, P.S., Aguilar-Gaxiola, S, Alonso, J, Angermeyer, M.C., Borges, G, Bromet, E.J., . . Wells, J.E. (2007). Use of mental health services for anxiety, mood, and substance disorders in 17 countries in the WHO world mental health surveys. Lancet, 370(9590), 841-850.

Wong, I. C., \& Murray, M. L. (2005). The potential of UK clinical databases in enhancing paediatric medication research. Br J Clin Pharmacol, 59(6), 750-755. doi: 10.1111/j.13652125.2005.02450.x

Wong, I. C., Murray, M. L., Camilleri-Novak, D., \& Stephens, P. (2004). Increased prescribing trends of paediatric psychotropic medications. Arch Dis Child, 89(12), 1131-1132. doi: 10.1136/adc.2004.050468

World Health Organization.). The ICD-10 Classification of Mental and Behavioural Disorders: Clinical descriptions and diagnostic guidelines Retrieved 24 May 2013, from http://www.who.int/classifications/icd/en/bluebook.pdf

World Health Organization. (2013). Application for inclusion to the 19th expert committee on the selection and use of essential medicines: risperidone. Retrieved 25 August 2013, from

http://www.who.int/selection medicines/committees/expert/19/applications/Risperid one 24 A Ad Final.pdf 